\title{
Just Kidding: Stand-Up, Speech Acts and Slurs
}

\author{
Peter Alward \\ University of Saskatchewan \\ DOI: $10.2478 /$ disp-2021-0001 \\ BIBLID [0873-626X (2021) 60; pp.1-25]
}

\begin{abstract}
People respond to moral criticism of their speech by claiming that they were joking. In this paper, I develop a speech act analysis of the humor excuse consisting of a negative stage, in which the speaker denies he or she was making an assertion, and a positive stage, in which the speaker claims she or he was engaged in non-serious/humorous speech instead. This analysis, however, runs afoul of the group identity objection, according to which there is a moral distinction between jokes targeting members of vulnerable groups made by members of those groups and similar jokes made by non-members. In order to avoid this objection, I offer a revision to the speech act analysis that draws upon Perry's distinction between beliefs and belief-states.
\end{abstract}

\section{Keywords}

Humor, speech acts, excuse, slurs, belief-states.

Michael Richards, during a notorious incident at a West Hollywood comedy club, repeatedly shouted 'FuckYou, $n * * * r$ ' and other racially insensitive comments to black audience members whom he judged to be interrupting his stand-up routine. The overwhelming consensus was that this was deeply morally problematic, even if he was joking at the time. Chris Rock, in contrast, in his stand-up routine entitled "Niggas vs. Black People", applied a variant of the same term to a subset of the black community and deployed a number of negative stereotypes about African Americans. But although the routine is controversial, the moral assessment of it has been far less negative. Similarly, Japanese comedian (and former wrestler) Razor Ramon Hard Gay has a routine in which he portrays a character from an American gay subculture. When it was revealed that he himself was not really gay but only pretending to be so, he was increasingly criti- 
cized for his stereotypical depiction of gay men.

The picture which emerges from these examples is one according to which the moral assessment of jokes that target members of a vulnerable group depends, in part, on whether the person who utters them is a member of that group. ${ }^{1}$ My goal in this paper is not to challenge this picture but rather to articulate how it could be correct. In particular, my goal here is to reconcile it with what I take to be a compelling account of the "humor excuse". Sometimes moral criticism of speech can be rebutted by pointing out that the speaker was joking rather than being serious. And one way of explaining this is in terms of differences between the commitments and presuppositions of serious and humorous speech acts. The trouble is that the commitments and presuppositions of speech acts do not seem to vary in the right way with the group membership of the speaker. As a result, both members and non-members of a targeted group appear to be equally well-placed to deploy the humor excuse.

This paper has five central sections. First, the basic issue of the appeal to humor to excuse speech, as well as a guiding example that is deployed to explore it, is introduced. Second, an account of humorous speech acts is developed, focusing on cases of fictional, as opposed to non-fictional, humor. Third, an analysis of the humor excuse framed in terms of humorous speech acts is expounded. Fourth, the "identity objection" to the speech act analysis of the humor excuse is presented and a number of possible solutions are both considered and found wanting. And finally, a novel solution to this problem is developed in terms of Perry's distinction between beliefs and belief-states.

\section{Preliminaries}

Stand-up comedy is differentiated from other forms of humor/comedy in a number of important respects. In this paper, the focus is going to be on one central differentiating feature, namely, that stand-up comedians perform substantial speech acts by means of their utterances. In a previous article, I argued that, unlike storytelling performances, neither the composition nor the dissemination of

\footnotetext{
${ }^{1}$ By targeting members of vulnerable groups, I mean targeting them on the basis of their membership in such groups and not for other reasons.
} 
written fiction involves making substantial speech acts (Alward 2010: 390-2). And the same point holds for written humor. By means of selecting and recording sentences - which the compositional process, at its core, consists in - an author need not need thereby make any assertions, requests, invitations, or what have you, or pretend to do any of these things. Moreover, there is little reason to believe that by giving a work of written humor to someone else to read, the author thereby performs speech acts corresponding to each of the sentences that make up the work. In contrast, spoken comedy - whether on stage or off-clearly does consist in the performance of substantial speech acts. And the exact nature of these speech acts is the topic of the next section.

It will prove helpful to focus the discussion here around an actual concrete example. Because the example involves spoken but off stage comedy, someone might worry that it cannot be used to support an account of stand-up speech acts. One possible rejoinder would be to argue that spoken humor always counts as impromptu stand-up: just as a public art installation temporarily transforms a public space into an ad hoc gallery - with concomitant changes in how objects are (prescribed to be) interpreted and appreciated — spoken comedy turns a locale into a temporary stage. But even if this is unpersuasive, it is worth noting that none of the discussion of the example is tied to the fact that it occurs off stage. In addition, in the last section the theory developed here will be applied to cases of spoken comedy that do occur on stage.

In 1997, during the NBA Western Conference Finals, Hannah Storm, a female sportscaster, interviewed Charles Barkley who then played for the Houston Rockets. During this interview he suggested to Storm that members of his team who had previously won NBA championships were playing without the same sense of urgency as those who had not yet won championships. Storm subsequently named the members of the team who had previously won championships and reasonably enough suggested that his criticism must have been intended to apply towards one or more of them. When he heard this, Barkley was outraged and accused Storm of taking his comments out of context, and he said the following:

“It doesn't surprise me though because it was Hannah Storm. Women 
shouldn't be announcing men's sports, anyway."

Barkley was widely criticized for his remarks and apologized to Storm in a subsequent interview, saying the following:

"It was stupid and sexist and said in jest. I want to apologize to you and all the women journalists out there. Keep up the good work."

There are three key elements of this example worth noting here. First, the fact that an utterance is intended as a joke, rather than meant seriously, is supposed to make a difference in the moral evaluation of the utterance. Other things being equal, Barkley's utterance of the sentence

Women shouldn't be announcing men's sports,

would be worse, morally speaking, if it were made seriously than if it were "said in jest". Second, simply claiming that an utterance was a joke does not make it so. Whether or not a speaker was joking depends, at least in part, upon his or her mental states at the time of the utterance. And a speaker could claim that his or her utterance was a joke either sincerely_-genuinely believing it to have been so-or insincerely_realizing it was not but trying to avoid moral criticism. And third, even if a claim to the effect that an utterance was joke is sincere (and accurate), this does not by itself render it morally unproblematic. Barkley had it just right: although it was (putatively) a joke, his remark was nevertheless "stupid and sexist" and warranted an apology. The point seems to be that while the humor excuse undermines one basis for the moral criticism of an utterance, other grounds for criticism remain in play and, perhaps, new bases for criticism may even be thereby generated.

The central concern here is twofold: the conditions under which morally suspect utterances can be excused by the appeal to humor, and the limits on such excuses. It is worth considering how these questions relate to more central questions in the current literature on the ethics of humor. These latter questions include such things as the conditions under which humor is wrong (Benatar 1999), whether or not we are responsible for finding morally inappropriate jokes funny (Sankowski 1977), and the extent to which moral defects in jokes affect whether or not they are in fact funny (Smuts 2010). My concern with the limits of the humor excuse accords nicely with questions 
about the wrongness of telling jokes and, perhaps less directly, with questions about responsibility for finding jokes funny. After all, the humor excuse fails exactly when an utterance would count as morally wrong even when understood to be a joke. But my concern with the conditions under which utterances can be excused by the claim that the teller was joking is an underdeveloped topic in the literature on the ethics of humor. Much of this literature is focused on the moral inappropriateness of (both telling and laughing at) certain forms of humor, whereas the focus in this essay is on humor that is morally appropriate and, in particular, the conditions under which understanding an utterance to be a joke renders it morally superior to what it would be if it were understood instead to be serious.

\section{Humorous speech acts}

Suppose that a sentence such as

Women shouldn't be announcing men's sports,

was uttered as an assertion. On a standard speech act analysis, the goal of an utterance is to effect a change in the psychological states or behavior of the person to whom it is directed by means of his or her recognition of the meaning or content of the utterance in the context in which it was produced (Grice 1957, Searle 1969, 1983). Typically, a distinction is drawn between communicative or "illocutionary" goals and actions and "perlocutionary" goals and actions designed to be achieved by means of illocutionary actions. And various kinds of speech acts are differentiated in terms of their characteristic illocutionary and perlocutionary goals. In the case of assertion, the characteristic perlocutionary goal is often taken to be that of getting the listener to believe what the speaker has said, or, more modestly, to believe that the speaker believes it. And the characteristic communicative goal is taken to be that of getting to the listener to recognize that the speaker intends to induce belief in what he or she has said, or, again more modestly, to express her or his commitment to the truth of what was said. In the example at hand, someone who uttered

Women shouldn't be announcing men's sports, as an assertion would have to have the perlocutionary goal of getting 
the listener to believe that women shouldn't be announcing men's sports and the illocutionary goal of getting the listener to recognize that the speaker intends the listener to believe that women shouldn't be announcing men's sports.

Speech acts can be sincere or insincere, but the requirements of sincerity vary with the type of speech act performed. In the case of assertion, sincerity requires that the speaker believe what is said. So, for example, a linguistically competent speaker who asserted the sentence

Women shouldn't be announcing men's sports,

but did not him or herself believe that women should not be announcing men's sports would be doing so insincerely and, in particular, would be lying. But any linguistically competent speaker who asserted that sentence sincerely would inevitably believe the proposition in question. As a result, the inference from the fact that a linguistically competent speaker made a sincere assertion by means of an utterance to the conclusion that the speaker believes what he or she said is a good one.

In addition to their sincerity conditions, speech acts normally come with a number of presuppositions. These are beliefs (and other attitudes) that need to be attributed to the speaker in order for his or her speech act to make sense. Although there may be a variety of different kinds of presuppositions required for the felicitous performance of a speech act of a certain kind, the focus here is on presuppositions that explain why the speaker said what he or she did, that is, why she or he produced an utterance with that particular meaning or content. The presuppositions of an assertion of

Women shouldn't be announcing men's sports,

for example, might include the belief that women lack the skill set to announce men's sports or something of that vein. As a result, both the belief that women should not be announcing men's sports and the belief that women lack the skill set to announce men's sports can reasonably be attributed to a linguistically competent speaker who sincerely asserts the sentence

Women shouldn't be announcing men's sports. 
Now, of course, the attribution of presuppositions of this kind to a speaker may be less epistemically secure than the attribution of sincerity conditions. After all, there may be multiple sets of beliefs that equally well explain the speaker's utterance. And which beliefs can be justifiably attributed to the speaker may depend on such things as conventional attitudes of the day, the trajectory of the conversation prior to the utterance at issue, and past behaviour-linguistic or otherwise - on the part of the speaker.

Other kinds of speech acts differ from assertions in both their characteristic goals and their sincerity conditions, as well as their presuppositions. Suppose, for example, that by means of uttering

I would like the salt,

I make a request rather than an assertion. In this case, my primary goal would be to have you pass the salt to me rather than to get you to form beliefs about my spice-acquisition preferences. And my speech act would be insincere if I did not want you to pass the salt, rather than if I did not believe that I would like the salt. The presuppositions of my utterance might include such things as the belief that you have the ability to pass the salt to me and would have the inclination to do so were you made aware of my desires on the matter. Similarly, if I made a promise, rather than an assertion, by means of uttering

I will pay you back tomorrow

my primary goal would be to commit myself to a future course of action rather than to induce beliefs about my future conduct in you. And my act would be insincere if I did not intend to carry out that action rather than if I did not believe that I would. The presuppositions might include the beliefs that I have the ability to pay you back - or, at least, that I will tomorrow - and that you want to be paid back.

The central concern here is with a speech act analysis of humor. In what follows, I will be focusing on cases in which the humorous utterances at issue are fictional as opposed to non-fictional. ${ }^{2}$ Of course, jokes often involve a mix of fact and fiction, that is, a mix of true and

\footnotetext{
${ }^{2}$ It is worth noting that it is the fictionality of humorous utterances, and not that of humorous works, that is at issue here. For more on the distinction between the fictionality of utterances and the fictionality of works, see Alward (2010).
} 
false (or, perhaps, truth valueless) utterances. Consider, for example, jokes designed to poke fun at specific people. By itself, of course, the truth of an utterance fails to render it non-fictional: after all, many fictions involve real people, places, and events. ${ }^{3}$ What is required instead for an utterance to be non-fictional is for it to be uttered as an assertion. ${ }^{4}$ Now one might try to deny that humorous utterances can be assertions, but this is hardly plausible even if tight restrictions are placed on the class of utterances at issue. After all, nothing prevents an arbitrary speaker from intending that a listener find what he or she says to be funny by means of inducing the listener to believe what was said.

The motivation here for focusing on humorous utterances that are fictional is that doing so seems to be a requirement of the humor excuse. As we shall see below, a central element of the attempt to excuse an utterance by claiming to have been joking is the denial that one's utterance was an assertion. As a result, any humorous utterance that is at the same time an assertion is not a candidate to be excused in this way. This is not to say that no humorous utterances are nonfictional; rather it is to say that non-fictional utterances cannot be excused by pointing out that they were humorous. ${ }^{5}$ The upshot is that non-fictional humorous utterances will not be at issue in the discussion here. One might object that, in at least some cases, the morally suspect content is not what is literally expressed by an utterance but rather what is pragmatically imparted by means of it. As a result, a speaker might be able to excuse her utterance by claiming to have been joking without having to deny that she was making an assertion in such cases. ${ }^{6}$ The trouble with this objection is that in order to ex-

${ }^{3}$ And non-fictional utterances can also be false.

${ }^{4}$ Requests, promises, and the like can, of course, be non-fictional as well. For present purposes, I will focus on the assertive case.

${ }^{5}$ One might attempt to develop an alternate variant of the humor excuse according to which an utterance can be excused, not by pointing out that it was humorous rather than an assertion, but by pointing out that it was humorous in addition to being an assertion. But insofar as an assertion is morally problematic in its own right, arguing that it was uttered to get a laugh seems to make things worse rather than better.

${ }^{6}$ This objection comes from an anonymous referee at Disputatio. 
cuse one's utterance by appeal to humor in some such case, the (putative) fact that one was joking would have to block the pragmatic inference from what one said to the problematic content. But it is simply not clear how this would work. Insofar as the claim to have been joking does not include a denial of having made an assertion, what it amounts to is the identification of an additional, perhaps unnoticed, perlocutionary goal of the utterance - having the audience find the utterance funny. But this provides no reason to think the utterance was not subject to the Gricean Cooperative Principle and its various maxims - or whatever mechanisms of pragmatic inference were in effect - and, hence, no reason to think that the problematic content was not pragmatically imparted even if the speaker was joking (Grice 1975). Unless and until an account can be developed according to which the perlocutionary goal of having the listener find what one says to be funny blocks the relevant pragmatic inferences, focusing on fictional cases will not lead us too far wrong.

The exact nature of the speech acts performed when engaged in fictional storytelling remains a matter of some controversy (Alward 2009). Two central approaches are Searle's (1975) pretense theory and Currie's (1990) fictive illocution theory. According to Searle's view, fictional speech consists of illocutionary pretense. If a speaker utters

It was a dark and stormy night

as part of a storytelling performance, he or she pretends to assert that the night in question was dark and stormy rather than actually doing so. As a result, he or she only pretends to meet the sincerity conditions of an assertion of that sentence - to have the belief that the night in question was dark and stormy - rather than actually doing so, and in addition only pretends that the presuppositions of some such assertion are satisfied. According to Currie, in contrast, speakers engaged in storytelling perform genuine illocutionary acts rather than pretending to do so. But rather than making assertions or promises or requests or the like, they engage in sui generis fictional illocutionary acts (Currie 1990). The characteristic perlocutionary goal of a fictional speech act, on the view in question, is that the listener imagine or make-believe the content of the utterance rather than believe it, and the characteristic illocutionary or communicative goal 
is that the listener recognize that the speaker intends that he or she make-believe it. So, for example, if a speaker utters

It was a dark and stormy night

as part of a storytelling performance, he or she genuinely performs an illocutionary act rather than pretending to do so; but rather than intending that the listener believe that the night in question was dark and stormy, the speaker's goal is to get the listener to imagine or make-believe that this is so.

In what follows, I am simply going to assume the goal of fictional speech is as the fictive illocution theory would have it. This is because even an advocate of the pretense theory would presumably take the goal of fictional speech to be that of getting the listener to be "caught up" in the fictional story; and the standard view of what this consists in is imagination or make-believe (Currie 1990, Walton 1990). Moreover, I am to assume that the sincerity condition endorsed by the fictive illocutionary view - that the speaker desires that the listener imagine or make-believe the content of her utterance - is satisfied as long as the speech in question is non-deceptive, that is, as long as the speaker does not intend that the listener believe the speech in question to be non-fictional. After all, insofar as the general goal of assertive pretense is listener make-believe and, in a particular case, the speaker has no intention to deceive, then the speaker will presumably desire that the listener imagine or make-believe what he or she says.

Now the question is what presuppositions a speaker must have if he or she engages in fictional speech. In particular, the question is what he or she must believe if she expects her utterance to have the desired effect on the listener. A minimal condition presumably is that the speaker must believe that what she or he says is imaginable: in order to reasonably expect that a listener will imagine or make-believe what he or she says, a speaker must believe that it is possible for the listener to do so. A second minimal condition is that the speaker must believe that what he or she says is comprehensible: in order to reasonably expect that a listener will imagine what she or he says, a speaker must believe that the listener understands him or her. And a third minimal condition is that the speaker must believe that what he or she says is sufficiently compelling: even if a listener understands what has been said and is able to imagine or make-believe it, he or she never- 
theless might not be inclined to do so; hence, in order to reasonably expect the listener to imagine what he or she says, a speaker needs to believe that the listener will find doing so sufficiently rewarding.

In addition to merely getting a listener to imagine or make-believe what she or he says, a speaker engaged in a storytelling performance will typically desire to achieve other effects as well, effects which paradigmatically vary with the genre of the story being told. A speaker telling an adventure story may hope to achieve excitement. A speaker telling a horror story may hope to achieve fear. And a speaker telling a tragedy may hope to achieve tears. ${ }^{7}$ In order to expect to produce these effects in listeners, speakers need to have as presuppositions two sorts of beliefs: beliefs about what features stories need to have in order to be exciting, scary, or sad; and beliefs which ground judgments to the effect that their own stories have these features. So, for example, I might expect a story in which an undergraduate with middling grades fails to get into law school to be sad if I believe that stories in which people fail to get what they deserve are sad and I believe that undergraduates with middling grades deserve to get into law school. ${ }^{8}$

The focus here, of course, is on humor in particular and not fiction more generally. The first thing to note is that in addition to merely getting the listener to imagine or make-believe what she says, a speaker engaged in (fictional) humorous speech will typically desire that the listener find what he or she says to be funny and, perhaps, to express this through laughter, facial expressions, or the like. Moreover, in order to expect her or his listeners to find what she or he says to be funny, the speaker, again, needs to have as presuppositions two sorts of beliefs: beliefs about what features a stretch of discourse needs to have in order to be funny; and beliefs which ground the judgment that what he or she says has these features. Consider again Charles Barkley's utterance of the sentence,

Women shouldn't be announcing men's sports.

${ }^{7}$ Of course, many stories are designed to achieve the paradigmatic effects of a plurality of genres.

${ }^{8}$ In what follows, I will be assuming that the speaker is not pandering, that is, saying things that he or she believes the speaker will find frightening, sad, or funny, but which he or she herself does not find frightening, sad or funny. 
Moreover, let us suppose that he was, as he claimed, joking and that his speech act was sincere in the sense that he really did want his audience to find what he said funny. In order to expect his utterance to have this effect he would have to presuppose something along the lines of the following: speech discussing people occupying roles for which they lack the temperament is funny; and women lack the temperament for announcing men's sports. There are, of course, different presuppositions that Barkley might have had that are compatible with the supposition that he was sincerely joking, but we will assume the presuppositions noted here for illustrative purposes.

\section{The humor excuse}

The humor excuse arises in circumstances of the following kind: a speaker has said something; an evaluator criticizes the content of what was said - and by extension, the speaker - as morally suspect; and the evaluator's criticism presupposes that the speaker's utterance was an assertion as opposed to a joke. ${ }^{9}$ There are, of course, other ways of avoid criticism of one's speech that falls short of denying you were being serious. A speaker might claim to have been misunderstood or that he or she was not being literal - that his or her utterance was meant metaphorically or ironically or sarcastically — or that he or she was being insincere. Alternately the speaker might concede the evaluator's interpretation but argue, contra the evaluator, that what he or she said was morally unproblematic. The focus here, however, is on cases in which the speaker concedes that the evaluator has got the content of her utterance right, that he or she was being sincere, and that if it had been uttered as an assertion, it would be morally problematic. But, in the cases at issue, the speaker nevertheless claims that his or her utterance is morally unproblematic because it was not an assertion, as he or she was joking.

In what follows, a two-stage analysis of the humor excuse will be developed. But it is worth noting at the outset that there are a number of other sorts of appeals to humor, distinct from the humor excuse at issue here, to which this analysis does not apply. One ex-

\footnotetext{
${ }^{9}$ Following Searle (1975), I will take non-serious speech to be fictional speech in general and humor to be a specific way of being non-serious.
} 
ample might involve cases in which an evaluator criticizes something a speaker has said when the status of the utterance in question as humor is not at issue. A speaker who responds to such criticism by saying that he or she was only joking is not thereby attempting to undercut that criticism by claiming that the utterance was a joke and not an assertion, but rather is claiming that the moral criticism of jokes in general is suspect (Bergman 1986: 75). Another example might involve cases in which an evaluator criticizes something the speaker has said when the status of the latter's utterance as non-humor is not at issue. I have in mind cases in which the speaker's claim to have been joking is a transparent pretense designed to de-escalate a potential confrontation provoked by his or her original utterance (which an evaluator, who is similarly disinclined towards confrontation, might pretend to believe).

The humor excuse can be analyzed as having two distinct stages, one negative and one positive. The negative stage consists in the denial that one was making an assertion; the positive stage consists in the affirmation that one was engaged in humorous speech. We will consider each in turn. Suppose someone makes an utterance whose content is morally problematic, perhaps because it is disparaging to the members of an oppressed or vulnerable group. If an evaluator judges the utterance to have been an assertion, he or she might rightfully criticize the speaker both for attempting to get the listening audience to believe this content and, assuming the speaker was sincere, for believing it him or herself, as well as believing any presuppositions of it there might be. So, for example, an evaluator who is made aware of Charles Barkley's utterance of the sentence,

Women shouldn't be announcing men's sports,

and who judges it to have been uttered as an assertion, might reasonably criticize him for both attempting to get others to believe that women shouldn't be announcing men's sports and for believing it himself. The negative stage of the humor excuse, assuming it is made sincerely, blocks these grounds for criticism. If the speaker denies that his or her utterance was an assertion, he or she thereby both denies that the goal of the utterance was to induce belief in the proble- 
matic content in the audience and denies believing it him or herself. ${ }^{10}$ So, for example, in claiming that his utterance of

Women shouldn't be announcing men's sports,

was made in jest, Charles Barkley thereby denied he was attempting to get the audience to believe that women should not be announcing men's sports and denied believing it himself.

As above, the positive stage involves the affirmation that the speaker was engaged in humorous speech. There are a number of worries one might have at this point. First, one might wonder whether or not the positive stage is even necessary, that is, whether a joke can be successfully excused by the negative stage alone. Consider, by way of analogy, someone found in possession of a murder weapon. Even if this person denies having committed the murder, unless he or she has an adequate excuse for possessing the weapon, she or he may still be in legal jeopardy. Similarly, someone who denies having made an assertion by means of an utterance nevertheless still performed some speech act or other by means of it. And depending on what type of speech act was thereby performed, the speaker might still be subject to moral criticism. The point of the positive stage of the humor excuse is to identify a speech act performed by means of the utterance - joke-telling - which renders the utterance morally innocent. Second, one might wonder whether or not the negative stage is required at all or if it is simply entailed by the positive stage. The first thing to note is that the positive stage does not entail the negative stage; after all, the possibility of non-fictional humor, discussed above, shows that the fact that one was joking does not entail that one was not making an assertion. Moreover, insofar as one has been subjected to moral criticism premised on the assumption that one's utterance was an assertion, the negative stage denial that one was making an assertion is essential to one's defense of the utterance. Third, one might wonder what the relation between the negative and positive stages actually is, whether the negative stage is temporally or logically prior to the positive stage, or whether there is some other relation between them. The first thing to note is that since both stages

${ }^{10}$ Strictly, all that the speaker thereby denies is having expressed some such belief, not merely holding it. 
are implemented by means of a single speech act — a statement to the effect that one was joking - there is little basis for thinking they fall into any kind of temporal order. The negative stage is prior to the positive stage in at least one other sense, however. Unlike the positive stage, it directly addresses the moral criticism that prompted the excuse: that the utterance at issue is morally problematic, if understood to be an assertion. Nevertheless, I remain neutral on the question of whether this counts as logical priority or some kind of pragmatic priority or the like. And fourth, one might wonder whether there are any theoretical benefits to the two-stage model over a simpler onestage model of the humor excuse. There is, in my view, one central advantage to the two-stage model: it can be deployed in the analysis of a broad range of excuses that are structurally similar to the humor excuse. In particular, it can be deployed whenever a speaker wants to claim that the moral criticism of one of his or her utterances has received is misguided because it misidentifies the speech act performed by means of the utterance. We have been focusing here on cases in which a speaker denies having made an assertion and claims instead to have been joking, but the two-stage could in principle be applied to any such speech act denial-claim pair, including the denial that one was joking and the claim one was making an assertion instead.

Now insofar as a speaker (sincerely) affirms that he or she was engaged in humorous speech, the speaker thereby commits him or herself to the following four things: (1) the goal that the listener imagine rather than believe what was said; (2) the goal that the listener find what was said to be funny; (3) general beliefs about what features a stretch of discourse needs to have in order to be funny; and (4) beliefs which ground the judgment that what was said has these features. And in order for the positive stage of the humor excuse to be effective, none of these commitments can themselves be morally problematic. Except under highly unusual circumstances, (1) and (2) are unlikely to be problematic. But given that certain styles of humor can be morally objectionable - graphically violent humor or humor that involves threats towards its targets, for example - a speaker's category (3) commitments can open him or her up to moral criticism. In addition, a speaker's category (4) commitments - beliefs that ground the judgment that what was said has the relevant funnymaking features - can also be morally problematic. After all, these 
beliefs might include morally suspect views about the target or targets of the joke. If it turns out that the speaker's category (3) and (4) beliefs are morally unproblematic, then the humor excuse is successful: the speaker has disavowed any morally problematic commitments his or her utterance would have had were it uttered as an assertion without taking on any other morally problematic commitments by affirming the utterance was made in jest. But if the beliefs are morally problematic - if, for example, they include harmful or demeaning stereotypes of members of oppressed or vulnerable groups - then the humor excuse is ultimately unsuccessful. Consider one final time Barkley's utterance of

Women shouldn't be announcing men's sports.

If, as above, Barkley's category (3) and (4) presuppositions were respectively that speech discussing people occupying roles for which they lack the temperament is funny and women lack the temperament for announcing men's sports, then by asserting that he was joking Barkley did not successfully excuse his utterance. And this is because he is drawing upon harmful stereotypes about women. That is why Barkley's own comment - "It was stupid and sexist and said in jest" (emphasis added) — was apt.

As noted above, the central concern addressed by the positive stage - the limits of the humor excuse - overlaps with some of the current literature on the ethics of humor. As a result, it is worth considering how the view on offer fits into this literature. The first thing to note is that the issue here is with the ethics of telling jokes and not the ethics of finding jokes funny. As a result, the view defended above does not in any direct sense address the question of the extent to which audiences are responsible for finding objectionable jokes they are told to be funny (Sankowski 1977, Smuts 2010). Second, the view on offer here has a number of affinities with Bergmann's account of sexist humor. According to Bergmann, humor counts as sexist when sexist beliefs must be held in order perceive the incongruity which makes the joke funny (Bergmann 1986: 70). Similarly, according to the positive stage of the humor excuse, the humor excuse fails - that is, the joke is morally inappropriate - exactly when the speaker has sexist or otherwise morally problematic beliefs which ground the judgement that his or her utterance is funny. Moreover, given the 
goal that the listener find what was said to be funny, the speaker must intend that the listener share these problematic beliefs as well. Third, despite its superficial differences from Benatar's account of the ethics of humor, the view on offer here is, at least arguably, compatible with it. According to Benatar, humor is wrong when it is either intended to cause harm or there is a reasonable expectation that it will do so, and the harm is not justifiable (Benatar 1999: 191). And an approach that analyzes unethical humor in terms of the harm it causes is prima facie incompatible with one which analyzes unethical humor in terms of morally problematic beliefs. But on Benatar's view, having a negative belief about someone harms that person by damaging their reputation, even if no action is taken on the basis of that belief (Benatar 1999: 193). As a result, the inappropriate beliefs which underpin my account of immoral humor count as the very sorts of harms which lie at the core of Benatar's account. Finally, one might object to the positive stage of the humor excuse developed above because it presupposes the claim that finding a joke funny requires believing the propositions it relies on rather than merely recognizing such propositions, a claim which is rejected by both Benatar (1999: 201) and Smuts (2010: 338). While it is true that the view on offer does presuppose this claim, it is worth noting if this presupposition is abandoned, the view could be easily reformulated on the model of the moderate autonomist position Carroll (1996) considers in his discussion of the relation between moral and aesthetic value. According to moderate autonomism, although an artwork can be rightfully criticized as being morally flawed, these moral flaws do not affect its aesthetic value. Similarly, one might argue that a joke can be morally criticized for engendering inappropriate beliefs even if sharing these beliefs is not required for finding the joke funny. This is only the barest of sketches of how my view might be reformulated, but it should suffice for present purposes.

\section{The identity objection}

In my view, this analysis of the humor excuse is basically correct, at least insofar as it is restricted to humorous utterances which are at the same time fictional. It captures how the claim to have been joking can excuse what someone says but also reveals the limits of some such 
excuse. Nevertheless, it runs into at least one serious difficulty: the group identity objection. The basic problem is as follows. According to the speech act analysis of the humor excuse, whether or not the claim that one was joking successfully excuses an utterance targeting the members of an oppressed or vulnerable group depends only on the speaker's beliefs about what features a stretch of discourse needs to have in order to be funny and his or her beliefs which ground the judgment that what was said has these features. But a non-member of the targeted group can have exactly the same beliefs on these issues as can a member of the group. And if they do have the same beliefs then the speech act analysis entails that the moral status of their utterances should be the same. Suppose, for example, that Chris Rock responded to moral criticism of an utterance from his "Niggas vs. Black People" routine by pointing out that he was joking and, moreover, that Rock's beliefs that ground his judgement that the utterance in question was funny pass moral muster. Given that there is no reason why Michael Richards could not share Rock's beliefs about what makes something funny, he could excuse a similar utterance from his West Hollywood club performance in the same way. But this runs counter to the assumption, made at the outset, that membership in a targeted group is morally significant.

There are two preliminary responses to this worry worth raising here: an epistemic response and an appeal to cultural meaning. First, according to the epistemic response, we find ourselves in a cultural context in which there are widespread discriminatory attitudes towards members of certain vulnerable groups held by people who are not members of them, attitudes which are not generally shared by the members of those groups themselves. As a result, other things being equal, it is reasonable to attribute discriminatory attitudes to nonmembers whose jokes target members of vulnerable groups, whereas it is reasonable to attribute non-discriminatory attitudes to members of those groups who tell the same sorts of jokes. And while the discriminatory attitudes attributed to non-members on this basis may well undermine any attempt to deploy the humor excuse on their part, the non-discriminatory attitudes attributed to members of the targeted group do not. The trouble with the epistemic strategy is that the attribution of widely shared discriminatory attitudes to a particular individual is epistemologically defeasible. Other evidence, including 
such things as the past behavior of the individual in question, the testimony of those who know him or her well, and the like, could warrant the attribution of non-discriminatory, rather than discriminatory, attitudes to the individual vis-à-vis the targeted group. And this leaves room for speakers who target members of vulnerable groups they themselves are not members of to avail themselves of the humor excuse. But suppose, for example, that the evidence supported the attribution to Michael Richards of non-discriminatory attitudes towards African Americans. I suspect that, even so, many people would resist the conclusion that his claim of having been joking would excuse his utterances during the performance in question.

Second, according to the appeal to cultural meaning, in a cultural context of widespread discriminatory attitudes, an utterance targeting members of a vulnerable group has a different cultural meaning when made by a member of the targeted group than it does when made by a non-member. Moreover, the cultural meaning of the utterance is independent of the attitudes of the person who made it. And if this is right, such differences in cultural meaning might render an utterance made by a non-member of the targeted group morally inappropriate even if the speaker shared the same attitudes as a member who said the same thing (and whose utterance was morally defensible). This strategy, however, runs into difficulties as well. One central difficulty stems from the fact that the cultural meaning of a symbol can vary with the social context in which it is deployed. Consider, for example, the swastika symbol. In most European and North American contexts, it symbolizes antisemitism and white supremacism; whereas in many southeast Asian contexts, it symbolizes well-being, prosperity, and luck. As a result, the cultural meaning of a joke targeting members of a vulnerable group made by a non-member depends on the context in which it is uttered. And not only does this yield a, perhaps unpalatable, kind of moral relativism regarding the moral status of such jokes, it also seems to entail that Michael Richards' utterances might have been morally appropriate had they only been made to a different audience. Once again, this is a conclusion I suspect many would resist. It seems that another strategy is required. 


\section{Indexical belief, group membership, and respect}

The defense of the speech act analysis of the humor excuse from the identity objection on offer here relies on Perry's distinction between beliefs and belief-states (1979). Perry's focus is on locating beliefs, beliefs about "where one is, when it is, and who one is" (Perry 1979: 5). What is significant about locating beliefs is that they both explain behaviour and can be expressed only by using indexical terms, such as 'I' or 'we'. Consider the follow example. Perry followed a trail of sugar down the aisles of a supermarket intending to inform the shopper with the torn sack that she or he was making a mess. At a certain point, Perry realized he was following himself down the aisles and thereby acquired the locating belief he expressed using the sentence 'I am making a mess.' As a result, he ceased following the trail of sugar and instead rearranged the sack of sugar in his shopping cart (Perry 1979: 3). What is important to note is that despite the fact that ' $\mathrm{I}$ ' in Perry's mouth and 'the shopper with the torn sack' refer to he same individual_-Perry himself — the locating belief at issue cannot be identified with Perry's belief that the shopper with the torn sack is making a mess. ${ }^{11}$ After all, since Perry had this belief all along, it cannot explain the change in Perry's behaviour from following the sugar trail to rearranging the sack in his own cart, which the locating belief, in contrast, does explain.

Perry's response to this problem is to take locating beliefs to be belief-states rather than beliefs proper. Beliefs are a certain kind of cognitive relation between subjects and propositions. So, for example, insofar as both Perry and I stand in the belief relation to the proposition that Perry was making a mess, it follows that we share the belief that Perry was making a mess. Belief-states, in contrast, are cognitive states that are individuated functionally - in terms of their contributions to behaviour — rather then in terms of any proposition to which the subject is thereby related. If, for example, Perry and I are both in cognitive states we would express using 'I am making a mess', we thereby believe different propositions: I believe the propositions that Peter Alward is making a mess and Perry believes the proposition that

${ }^{11}$ Or any other belief that could be expressed by Perry without the use of the indexical 'I', for that matter. 
John Perry is making a mess. Nevertheless, insofar as we both desire to avoid making messes - and believe that messes can be avoided by rearranging torn sugar sacks - we will engage in the same sack rearranging behaviour. It is it for this reason that we count as being in the same belief-state (Perry 1979: 17-8).

The structure of the defense of the speech act analysis on offer here is a follows: there is a psychological state that members of a vulnerable group can be in but non-members cannot be in; and being in that state makes a difference vis-à-vis the moral status of jokes targeting members of the group. Borrowing from Perry's discussion of locating beliefs, the state in question is one that can be expressed only by uses of 'we' whose extension is the membership of the group targeted by the joke: since members of a targeted group can use 'we' in this way, they can be in this state; but since non-members do not fall within the extension of such uses of 'we', they cannot be in this state. There are two questions that arise at this point: exactly what the psychological state in question is; and why does being in this state make a moral difference when it comes to jokes targeting members of vulnerable groups.

In the remainder of this section, I will defend the view that the psychological state which grounds the moral distinction between jokes targeting a vulnerable group made by members and non-members is self-respect as a group member. The question as to why being in some such cognitive state is morally significant can be sharpened by focusing on cases in which the speaker targets another person, rather than a group, with a joke. The first thing to note is that there is a fundamental moral distinction between those cases in which the speaker is poking fun at the target of the joke and those cases in which he or she is treating the target like a buffoon. Other things being equal, poking fun at someone is morally permissible but treating her or him like a buffoon is not. ${ }^{12}$ And what distinguishes poking fun at someone and treating him like a buffoon is respect: if I respect the target of my joke then I am merely poking fun at her or him; but if I fail to res-

\footnotetext{
${ }^{12}$ Exceptions include cases where the target is particularly thin-skinned - and so even poking fun of him might not be acceptable - as well as cases where the target has engaged in serious wrongdoing - in which case treating him as a buffoon might be permissible.
} 
pect the target — or, more strongly, disrespect her or him — then I am treating the target like a buffoon. ${ }^{13}$

But even if I respect the target of my joke, there remains a moral asymmetry between cases in which I make fun of her or him and the target makes fun of her or himself. Suppose, for example, that the target is very obese. Although it might be permissible for said person to make fat jokes about him or herself, other things being equal it would still not be permissible for me to make fat jokes targeted at him or her. And I take it that the reason that it would be inappropriate is because obese people are systematically treated in disrespectful (or worse) ways because of their weight. As a result, targeting an obese person with a fat joke contributes to a pattern of abuse, even if I respect the target of my joke. ${ }^{14}$ But if the obese person makes a fat joke about her or himself, it need not contribute to this pattern. In particular, if it is made with an attitude of self-respect, it can transform the socially maligned feature into a source of personal power, which can be used to undermine or blunt the abusive behaviour to which he or she has been subjected. ${ }^{15}$

It is important, for present purposes, to note that people are multifaceted: they have a variety of features which ground their membership in a corresponding variety of groups. For example, someone might be both a professional philosopher and an alcoholic, among other things. Moreover, people often are in a state of self-respect qua membership in some groups but lack self-respect qua membership in others. So, for example, someone might have self-respect while conceiving of her or himself as a professional philosopher but lack selfrespect while conceiving of him or herself as an alcoholic. ${ }^{16}$ And in

${ }^{13}$ Please note that the form of this pair of conditionals is "If P then Q" and "If not-P then R" rather than "If $\mathrm{P}$ then Q" and either "If Q then P" or "If not- $\mathrm{Q}$ then not-P”.

${ }^{14}$ There may, of course, be special circumstances in which, due to a unique relationship between the joker and the target, or the like, the joke remains nonabusive.

${ }^{15}$ But if the joke is made without self-respect, the target is arguably contributing to his own abuse.

${ }^{16}$ And this can be true whether or not she or he has self-respect in a more fundamental sense as a person. 
the case at hand, what is important is not that the speaker at issue has self-respect as a member of some group or other, but rather that he or she has self-respect as a member of the group targeted by a joke she or he utters. Consider, again, the contrast between Michael Richards' utterances during his notorious West Hollywood performance and Chris Rock's utterances from his "Niggas vs. Black People" routine. Now both Richards and Rock presumably have self-respect as members of a number of different groups, perhaps including self-respect as comedians. But Richards, unlike Rock, simply cannot be in a state of self-respect as an African American because he is not a member of that group. As a result, other things being equal, Richards' utterances contribute to a pattern of discrimination against African Americans, even if he has the same beliefs about what is funny that Rock does and even if he has non-discriminatory attitudes towards African Americans more generally. But insofar as Rock is in a state of self-respect as an African American, his utterances are at least candidates to pass moral muster.

\section{Conclusion}

The goal of this paper was twofold: to offer a speech act analysis of the humor excuse; and to defend this analysis from the identity objection. First, according to the analysis developed here, the humor excuse consists of a negative stage, in which the speaker denies he or she was making an assertion, and a positive stage, in which the speaker claims she or he was engaged in non-serious/humorous speech instead. And, according to this analysis, the humor excuse is successful only if the beliefs that ground that speaker's judgment that his or her utterance was funny are morally unproblematic. Second, according to the response to the identity objection offered here, in cases in which the joke targets members of a vulnerable group, the speaker needs to be in a state of self-respect as a member of the group in question - in addition to having morally acceptable beliefs about what makes his or her utterance funny - in order for the humor excuse to be successful.

There are two final comments worth making about the conclusions reached here. First, the structure of the response to the identity objection developed above is independent of the particular psycholo- 
gical state - self-respect as a member of the targeted group - that is embedded in it. One could retain the overall structure of this defense of the speech act analysis while deploying a distinct psychological state which is available only to members of the targeted group. Second, the conclusion here is not that a non-member can never permissibly make a joke targeting members of a vulnerable group, but rather that, other things being equal, it is morally worse for a non-member to do so than a member. There may well be circumstances in which a non-member can permissibly tell a joke which targets a member of a vulnerable group - if, for example, the humor is gentle, there is a relation of mutual respect between the joker and the target, the joke is told in a private setting, etc. But an implication of the view on offer is that doing so is always morally risky. Finally, if anyone finds anything I have said here to be even remotely problematic, let me assure you that I was just kidding.

Peter Alward Department of Philosophy University of Saskatchewan

9 Campus Dr.

Saskatoon, SK S7N 5A5

Canada

peter.alward@usask.ca

\section{References}

Alward, Peter. 2009. Onstage illocution. Journal of Aesthetics and Art Criticism 67(3): $321-31$.

Alward, Peter. 2010. Word-sculpture, speech acts, and fictionality. Journal of Aesthetics and Art Criticism 68(4): 389-99.

Benatar, David. 1999. Prejudice in jest: when racial and gender humor harms. Public Affairs Quarterly 13(2): 191-203.

Bergmann, Merrie. 1986. How many feminists does it take to make a joke? sexist humor and what's wrong with it. Hypatia 1(1): 63-82.

Caroll, Noël. 1996. Moderate moralism. British Journal of Aesthetics 36(3): 223-38.

Currie, Gregory. 1990. The Nature of Fiction. Cambridge: Cambridge University Press.

Grice, Paul. 1957. Meaning. Philosophical Review 66: 377-88.

Grice, Paul. 1975. Logic and conversation. In Syntax and Semantics, vol. 3: Speech Acts. Edited by P. Cole and J.L. Morgan. New York: Academic Press.

Perry, John. 1979. The Problem of the essential indexical. Nous 13(1): 3-21.

Saltz, David. 1991. How to do things on stage. Journal of Aesthetics and Art Criticism 49(1): 31-45.

Sankowski, Edward. 1977. Responsibility of persons for their emotions. Canadian 
Journal of Philosophy 7(4): 829-40.

Searle, John. 1969. Speech Acts: An Essay in the Philosophy of Language. Cambridge: Cambridge University Press.

Searle, John. 1975. The logical status of fictional discourse. New literary History 6: 319-32.

Searle, John. 1983. Intentionality. Cambridge: Cambridge University Press.

Smuts, Aaron. 2010. The ethics of humor: can your sense of humor be wrong? Ethical Theory and Moral Practice 13(3): 333-47.

Walton, Kendall. 1990. Mimesis as Make-Believe. Cambridge: Harvard University Press. 